\title{
Evaluation of South African Chenin Blanc Wines Made From Six Different Trellising Systems Using a Chemical and Sensorial Approach
}

\author{
V. Panzeri, H.N. Ipinge, A. Buica* \\ Department of Viticulture and Oenology, Stellenbosch University, Private Bag X1, Matieland, 7602, South Africa
}

Submitted for publication: February 2020

Accepted for publication: April 2020

Key words: Trellising systems, wine, sensory evaluation, chemical composition, check-all-that-apply (CATA), high-resolution mass spectrometry (HRMS), Chenin blanc

\begin{abstract}
There are many ways of manipulating the components of grape berries and one of these is the implementation of a specific trellising system. This will affect light exposure in the bunch zone, air flow through the canopy, crop load, etc., and consequently the primary metabolites that contribute to the production of secondary compounds in wine. The aim of the present study was to characterise the grape musts and wines of Chenin blanc made from grapes of different trellising systems, using chemical fingerprinting of the samples and the check-all-that-apply method, combined with a quality scoring test. The results indicate that, while the wines could not be separated according to treatment from an aroma point of view, the grapes produced by different trellis systems resulted in wines characterised by differences in taste and mouthfeel. The present study shows that trellising systems can influence amino acids, yeast assimilable nitrogen, phenolic content and aroma compounds, as well as sensory characteristics. In this case study, wine quality was not affected by the trellising systems, with one exception. Fingerprinting using high-resolution mass spectrometry proved to be a successful tool to separate the samples according to the systems.
\end{abstract}

\section{INTRODUCTION}

Chenin blanc belongs to a group of grape varieties defined as 'neutral' (Augustyn \& Rapp, 1982); for this reason, the style of the resulting wines is dictated by the winemaking process, as well as the manipulation of the vines' microclimate. Young Chenin blanc wines exhibit a fruitlike aroma as a result of volatile esters formed during fermentation, but additional or different aromas can be induced by canopy management practices aimed at modifying the physiology of the grapevine, and therefore some of the derived grape precursors (Reynolds \& Vanden Heuvel, 2009). Furthermore, the choice of yeast strain (Reynolds et al., 2001), yeast strain nutrition (Van Rooyen \& Tromp, 2017), skin-contact time (Marais \& Rapp, 1988) and pressing (Somers \& Pocock, 2015) are amongst the oenological practices that alter the content and concentration of volatiles and non-volatiles in juices or wines.

One of the significant ways of manipulating the canopy, and subsequently the grape, must and wine composition and sensory profile, is modifying the architecture of the vines with different trellising systems. Generally, training systems make a difference in maintaining a balance between the fruitproducing parts and the energy-producing structure, different degrees of exposure to light in the bunch zone (Marais et al., 1992), as well as proper air flow through the canopy to avoid conditions favourable for fungal infections (Van Zyl \& Van Huyssteen, 1980b). In the specific case of sun exposure, such factors affect the content of vine metabolites constituting the grape volatile profile and aroma reservoir (Reynolds et al., 1996), and consequently wine aroma (Zoecklein et al., 2008). Many of these influences occur in aromatic varieties such as Riesling (Reynolds et al., 1996), Viognier (Zoecklein et al., 2008), Sauvignon blanc (Marais et al., 1999) and, to some extent, in Chardonnay grapes (Zoecklein et al., 1998). It has been demonstrated that training systems influence grape quality components such as sugars, acids, phenols and primary aroma compounds (Reynolds et al., 2004; Ji \& Dami, 2008; Zoecklein et al., 2008). However, assessing the evolution of these components through to wine is not as complete.

The overall quality of wine is determined by several properties, including colour, aroma and taste perceptions, which are all equally important for consumer acceptance (Charters \& Pettigrew, 2006). The aroma profile of a wine results from a combination of various compounds present in the grapes or derived from the fermentation and ageing processes (Ribéreau-Gayon et al., 2006). A lot of volatile compounds are present in low concentrations $(\mu \mathrm{g} / \mathrm{L}$ and lower); however, they play a significant role in nuances in 
wine aroma. These compounds emerge from heterogeneous classes such as alcohols, esters, acids, terpenes, phenols and aldehydes, as well as sulphur compounds (Ferreira et al., 2000; Jeffery et al., 2012).

Neutral varieties like Chenin blanc obtain aromas from the fermentation process (Du Plessis \& Augustyn, 1981; Augustyn \& Rapp, 1982), and thiols have also been demonstrated to contribute to wine aroma (Wilson, 2017). Moreover, thiol precursors are one of the classes of molecules influenced by various vineyard practices (Kobayashi et al., 2011). Practices such as leaf removal have a significant influence on grape composition and wine quality (Marais et al. 1992, 1999). The ability of the trellis to expose canopies to sunlight and eventually to the impact of the surrounding environment, and the accumulation of organic compounds (Van Zyl \& Van Huyssteen, 1980a, 1980b) also influence wine quality (Volschenk \& Hunter, 2001).

To assess the quality of food and beverages, a number of sensory evaluation methods have been used (Lawless \& Heymann, 2010). In the evaluation of wines, the judgment of quality is consigned to winemakers or experts. Qualityjudging systems have been applied based on points, a popular method being the 20-point scale developed by the University of California Davis to evaluate wine sensory properties for quality control and commercial purposes. In this method, points are assigned in sensory categories such as appearance, aroma, taste and overall quality, with a possible total of 20 points. Most studies have used this system to assess the quality aspects of wine. However, although this method is suitable for general quality assessment, it may not distinguish among the group of wines of high quality, since it is based on penalisation for defects from the typicality of the wine style. Also, points allocation for each category gives a different weight to the sensory characteristics, which may or may not reflect their importance in the overall quality.

To address these problems, descriptive analysis (DA) can be coupled with this system to characterise sensory differences in wines across multiple attributes, as has been demonstrated for Cabernet Sauvignon and Chardonnay wines (Niimi et al., 2018). DA uses both qualitative and quantitative methods in the evaluation of a product, but also has some drawbacks: panellists need training, so it is time-consuming and leads to additional costs. Therefore, researchers have developed alternative applicable methods for the characterisation of wines that produce similar results but use rapid techniques (Valentin et al., 2012).

One of the alternative methods that have gained popularity is check all that apply (CATA), originally used in marketing (Rasinski et al., 2002) and subsequently proposed as an alternative method in the food industry to gather information about consumers' perceptions (Adams et al., 2007). CATA is a rapid sensory-profiling technique that uses a questionnaire consisting of a list of attributes (in the form of words or phrases), from which trained or untrained panellists can select all the descriptors they consider appropriate to characterise each sample (Valentin et al., 2012). In the South African wine industry, CATA has been used to characterise the aroma profile of Chenin blanc in both experimental (Botha, 2015) and commercial wines (Buica \& Panzeri, 2018), as well as in Pinotage commercial wines (Panzeri et al., 2019).

The main analytical technique applied for the investigation of volatile compounds in wine is gas chromatography (GC), coupled with FID or mass spectrometry (MS). Although this technique is applicable for targeted and untargeted analysis, it has limitations and disadvantages, such as the inability to directly identify non-volatiles and the high cost of the equipment.

In cases where a list of analysis is incomplete, and also when wine matrices have a significant effect on suppressing or enhancing aromatic expression, it is worthwhile exploring additional methods. The most viable approach is untargeted metabolomics, a comprehensive analysis of metabolites that reveals a chemical fingerprint. Metabolic profiling has been successful in characterising grape and wine typicality and quality (Atanassov et al., 2009), and profiling wine according to variety (Vaclavik et al., 2011) and phenolic compounds (Salvatore et al., 2013). Fingerprinting allows the extraction of hidden information from the acquired multidimensional data, for instance to authenticate wine using LC-HRMS (Rubert et al., 2014) or attribute wine styles to commercial Chenin blanc (Buica et al., 2017).

The aim of this study was to investigate the effects of canopy microclimate manipulation through trellising systems on the chemical and sensory profiles of Chenin blanc wines. From a chemical point of view, and despite more readily available advanced analytical methods for the identification and quantification of the chemical composition of wines together with multivariate analysis, no work has been done on the characterisation of wines made from different trellising systems to date. To achieve the profiling of the products, wine fingerprinting by LC-HRMS was done, coupled with principal component analysis (PCA) and hierarchy cluster analysis (HCA). From a sensory point of view, the hypothesis proposed was that aroma, taste and mouthfeel are affected by changes in the canopy. While previous studies have assessed the impact of oenological and other viticulture aspects from a chemical point of view, there is no study that has evaluated the sensory profile of wines from different trellising systems. Given the previously outlined advantages of the method, CATA was chosen for this study. In addition, quality rating with industry experts was investigated to evaluate the effect of yield variation on the marketable characteristics of the wines produced.

\section{MATERIALS AND METHODS}

\section{Experimental vineyard}

Grapevines (Vitis vinifera L. cv. Chenin blanc clone SN 24B grafted onto $110 \mathrm{R}$ rootstock) were planted in a single block in 2010 and trained to six different systems, namely: Santorini (S), Ballerina (B), Smart Dyson (SD), T-Frame (TF), Lyre (L) and 'Stok-by-Paaltjie' (P), also known as 'staked vines' or 'Echalas'. Each system was planted in a different row. The vineyard is located on one of the oldest Cape Dutch farms in the Franschhoek valley region, Western Cape, South Africa (3349'23.4's latitude and 1855'29.4"E longitude). The experiment was conducted over two vintages, namely 2017 and 2018, as listed in Table 1. All vineyard practices, including irrigation and pruning, were applied uniformly to all treatments by the estate. 


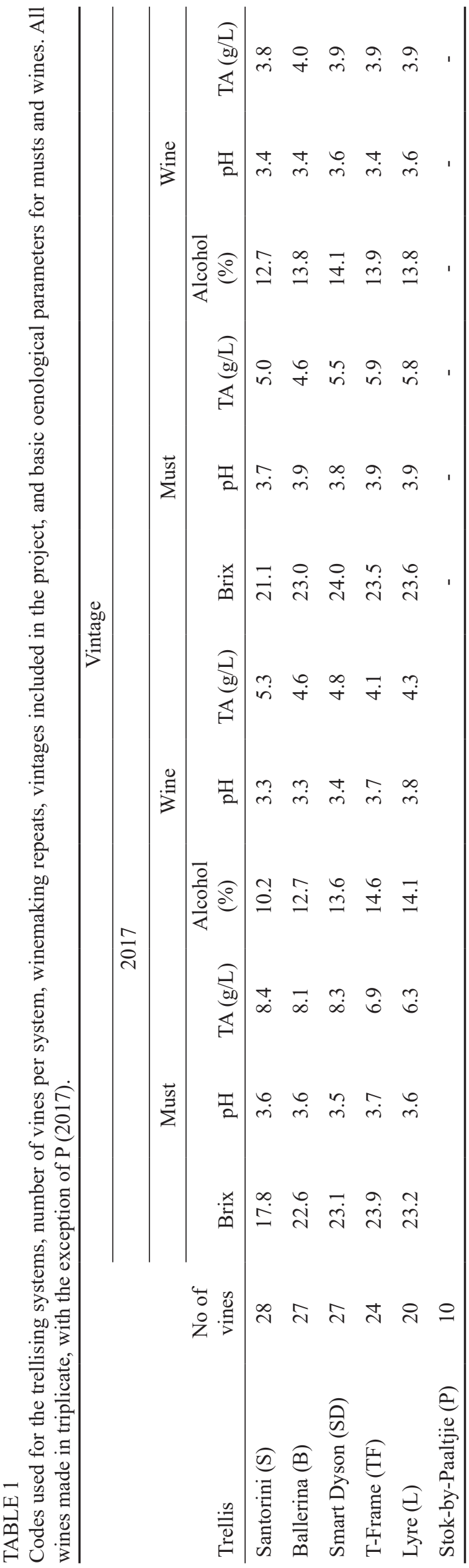

\section{Vinification process and wines}

Grapes were harvested at $22 \pm 0.5^{\circ} \mathrm{B}$ in both vintages. Harvested grapes from the vineyard were transported to the experimental cellar of the Department of Viticulture and Oenology (DVO) of Stellenbosch University. The grapes were weighed and the yield of each type of trellising system was recorded, after which the grapes were refrigerated overnight at $4{ }^{\circ} \mathrm{C}$. The following day, the grapes were destemmed and crushed with the addition of $40 \mathrm{mg} / \mathrm{L} \mathrm{SO}_{2}$ and $0.03 \mathrm{~g} / \mathrm{kg}$ of pectolytic enzyme (Lafazym Extract enzyme, Laffort, South Africa). Skin contact was allowed for two to three hours. Pressing was done by vertical hydropress at one cycle up to 1 bar. Rapidase ${ }^{\circledR}$ Clear Enzyme, at $4 \mathrm{~mL} / 100 \mathrm{~L}$ (Laffort, South Africa), was added to the juice and left overnight in a $4{ }^{\circ} \mathrm{C}$ refrigerated room to help juice settling and clarification. Biological repeats were separated in the cellar before inoculation. The must was treated with $50 \mathrm{mg} / \mathrm{L} \mathrm{SO}$, inoculated with Saccharomyces cerevisiae strains Vin7 and Vin13 (ANCHOR YEAST Zymasil@, AEB Group SpA, Bologna, Italy) in a ratio of 50:50, previously rehydrated according to the manufacturer's instructions, and then transferred into $20 \mathrm{~L}$ stainless-steel tanks for vinification. All wines were made in triplicate, except for the P treatment in the 2017 season, as there was only enough crop to make two replicates. Fermentation was carried out at $15^{\circ} \mathrm{C}$ until completion (about 14 days). Wines were racked into $20 \mathrm{~L}$ stainless-steel tanks and placed at $15^{\circ} \mathrm{C}$. All wines were left in contact with the fine lees for three months prior to bottling and were gently stirred twice a week without opening the canisters to avoid oxidation. After this period, the wines were racked off and $50 \mathrm{~g} / \mathrm{hL}$ of bentonite was added prior to cold stabilisation. The tanks were placed in a $-4^{\circ} \mathrm{C}$ refrigeration room for two weeks. The cold-stabilised wines were bottled and stored at $15^{\circ} \mathrm{C}$ for six months until the chemical and sensory analyses were performed. Wine evaluations are summarised in Fig. 1.

\section{Chemical analyses}

\section{Oenological parameters}

Grape berries were monitored before harvesting and analysed after crushing for sugar concentration (Brix), using a handheld refractometer (PAL1, Atago). $\mathrm{pH}$ and TA were measured with a potentiometric titrator (702 SM Titrino, Metrohm). Wine ethanol was quantified by infrared spectroscopy using the Winescan FT120 spectrometer (FOSS Analytical, Denmark), and in-house calibrations were done as described by Nieuwoudt et al. (2004).

\section{Nitrogen composition}

Racked juice samples were analysed for ammonium and free amino nitrogen (FAN), the sum of which gives yeast assimilable nitrogen (YAN). The analysis was done at VinLab (Stellenbosch) for both the 2017 and 2018 harvest years, using enzymatic methods according to ISO 17025 standards.

Twenty amino acids were quantified for the 2017 juice samples as described in Petrovic et al. (2019), using a derivatisation method based on labelling with AccQTag(C (Waters), with Norvaline (Nvl) as internal standard, followed by determination by LC-UV/Vis at the Mass Spectrometry 


\section{7}

2018

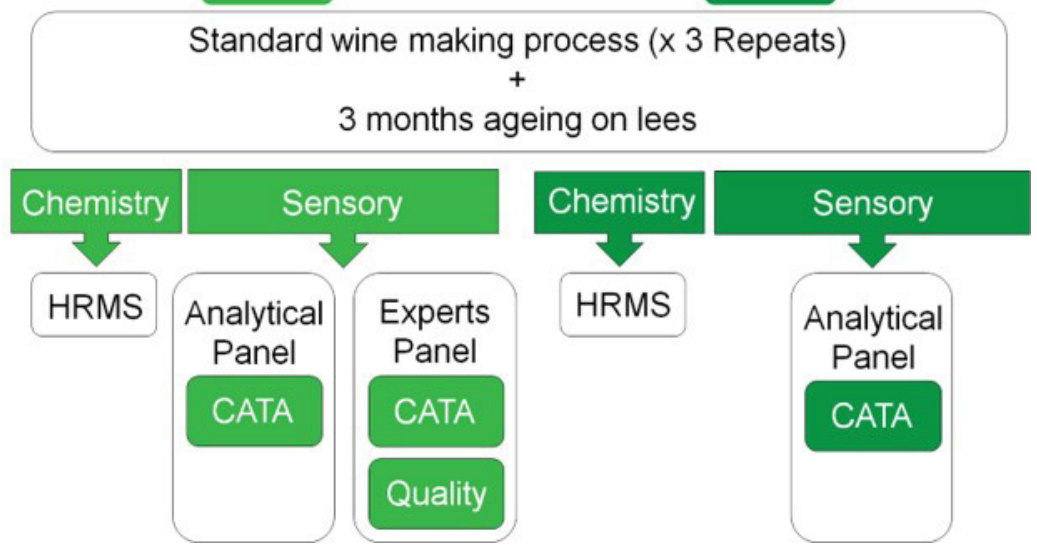

FIGURE 1

Workflow indicating winemaking repeats, the stage at which wine evaluation took place, and the chemical and sensory tests performed

Unit of the Central Analytical Facility of Stellenbosch University. Alanine, arginine, asparagine, glutamic acid, glutamine, glycine, histidine, hydroxyproline, isoleucine, leucine, lysine, methionine, phenylalanine, proline, serine, threonine, tryptophan, valine, gamma-aminobutyric acid (GABA) and ornithine were quantified.

\section{Major volatiles}

Wines samples for 2017 and 2018 were quantified for major volatiles using the GC-FID method described by Louw et al. (2010). In brief, $5 \mathrm{~mL}$ wine samples were spiked with methyl-pentanol as internal standard, and extracted with $1 \mathrm{~mL}$ ether. The extract was dried over anhydrous $\mathrm{Na}_{2} \mathrm{SO}_{4}$ and injected in duplicate into a GC-FID (HP-6890, Agilent).

\section{Thiols}

The volatile thiols, 3-mercaptohexan-1-ol (3MH), methyl4-mercaptopentan-2-one (4MMP) and 3-mercaptohexylacetate (3MHA), were quantified following the method of Mafata et al. (2018), using DTDP derivatisation, SPE sample clean-up, and injection into a convergence chromatography-tandem mass spectrometry instrument (UPC2-MS/MS, Waters).

\section{High-resolution mass spectrometry (HRMS)}

HRMS coupled with liquid chromatography (LC-HRMS) was used for wine fingerprinting. The samples were analysed by UPLC (Waters Corporation) equipped with a Synapt G2 quadrupole time-of-flight mass spectrometer (Waters Corporation). The separation was done on an Acquity UPLC HSS T3 column (1.8 $\mu \mathrm{m}$ internal diameter, $2.1 \mathrm{~mm}$ x $100 \mathrm{~mm}$, Waters Corporation) using $0.1 \%$ formic acid (mobile phase A) and acetonitrile (mobile phase B), and a scouting gradient. The flow rate was $0.3 \mathrm{~mL} / \mathrm{min}$ and the column temperature was $55^{\circ} \mathrm{C}$. The injection volume was $2 \mu \mathrm{L}$. The software is integrated directly with SIMCA-P (Umetrics) and the statistical algorithms are applied directly to the processed datasets (Buica et al., 2017).

\section{Sensory evaluation}

\section{Panels for sensory evaluation}

Two separate groups of participants were selected for the project: a panel of thirty industry experts and a panel of ten analytical (trained) panellists. Experts were recruited on the basis of their experience, interest and availability. The age group varied from 26 years to 45 years old (six women and 24 men, 30 answers in total). Experts only assessed wines of the 2017 vintage. The analytical panellists were selected based on their experience in wine profiling using multiple sensory methods and were often recruited by the Department of Viticulture and Oenology (Stellenbosch University) for sensory evaluations. Their ages varied from 26 to 66 years old; in 2017 there were 10 women, whereas in 2018 the panel consisted of eight women and two men.

\section{Sensory sessions}

The evaluation was done six months after bottling. Prior to sensory evaluation by experts, the wines were screened and wines from the same treatment were blended. Blending was done to meet the volume of wine required, and also for quality-assessment reasons. Therefore, the experts evaluated six wines (blended) representing six trellising systems, while the analytical panel evaluated the six wines with their biological repeats.

The sensory tests were carried out in two separate sessions. The first session involved the industry experts and was carried out at the Paul van der Byl Laboratory (Stellenbosch University) in a well-ventilated, naturally lit room kept at \pm $20^{\circ} \mathrm{C}$. Experts were tasked with evaluating aroma, taste and mouthfeel using the CATA method and, secondly, evaluating the quality using the 20-point scale method. The second session involved the analytical panellists and was carried out in the sensory laboratory of the Department of Viticulture and Oenology of Stellenbosch University. The laboratory is designed specifically for sensory analysis (ISO 8589) and contains individual tasting booths in which the temperature and humidity are controlled. For the CATA method, both experts and analytical panellists used black glasses, and wine 
samples were poured 20 minutes prior to testing and covered with Petri dishes. In addition, the expert tasters were served a supplementary set of the same wines in clear ISO glasses for quality scoring in order to allow them to evaluate the appearance of the samples. Twenty millilitre samples were dispensed using a measuring device and maintained at a temperature of $20^{\circ} \mathrm{C}$.

CATA aroma terms used in this study were selected from the South African Chenin blanc aroma wheel. The taste and mouthfeel attributes were chosen by a focus group after a preliminary screening of the wine samples. The total list of descriptors used for this exercise comprised 40 words. The analytical and expert panels were instructed to evaluate aroma as well as taste, and to check all the terms they considered appropriate for describing each sample. The samples were coded with individual three-digit codes and randomised across panellists according to a William Latin square design. With the experts, the exercises were conducted in one day. They evaluated two flights: in the first flight, they were asked to evaluate aroma and taste, and in the second flight wine quality based on the three aspects (appearance, aroma and taste) using the 20-point scorecard. The analytical panel was only tasked with evaluating aroma and taste, done in three flights over three days (three technical repeats, resulting in 30 answers).

\section{Statistical analysis \\ Chemical data}

Principal component analysis (PCA) and hierarchical cluster analysis (HCA) were applied in order to find natural configurations in the data according to treatments and samples by grouping/clustering (SIMCA 14.1, Umetrics, Sweden). Additional data analysis and graphical representations were performed using Microsoft Excel 2013.

\section{Sensory data}

Data was captured using Compusense ${ }^{\circledR}$ at-hand software (West Guelph, Ontario, Canada) and analysed on XLStat 2018.5 (Microsoft, www.xlstat.com). Correspondence analysis (CA) was performed on a contingency table using Statistica ${ }^{\circledR} 13.3$ software. Graphical representations of the sensory profiles, including aroma, taste and mouthfeel characteristics, were provided as bi-plots by plotting the mean values for the sensory descriptors. Least significant differences (LSD) were calculated between wines by analysis of variance (ANOVA) using the Statistica ${ }^{\circledR} 13.3$ program, and the results were evaluated at the $95 \%$ confidence level for quality scores.

\section{RESULTS AND DISCUSSION \\ Results of chemical evaluation Nitrogen composition of the must}

YAN levels of the musts were higher in 2018, ranging from $270 \mathrm{mg} \mathrm{N} / \mathrm{L}$ to $353 \mathrm{mg} \mathrm{N} / \mathrm{L}$, compared to 2017, with a range of $173 \mathrm{mg} \mathrm{N} / \mathrm{L}$ to $267 \mathrm{mg} \mathrm{N} / \mathrm{L}$. All values were above the "critical level" of 140 to $150 \mathrm{mg} \mathrm{N} / \mathrm{L}$ (Table 2). The concentration differed significantly between the systems in 2017, whereas there were no significant differences in 2018. The juices from the $\mathrm{L}$ system had the highest level of YAN concentration on average, at $247 \mathrm{mg} \mathrm{N} / \mathrm{L}$ and $353 \mathrm{mg}$ $\mathrm{N} / \mathrm{L}$ in the two seasons, respectively, while the lowest YAN concentration was found in the SD system, at an average of $173 \mathrm{mg} \mathrm{N} / \mathrm{L}$, and the $\mathrm{S}$ system, at $270 \mathrm{mg} \mathrm{N} / \mathrm{L}$, for 2017 and 2018 , respectively.

The current results are in agreement with the average concentration of free amino nitrogen and ammonia concentration in South African Chenin blanc must (Petrovic et al., 2019). S had the highest concentration, at $70 \mathrm{mg} \mathrm{N} / \mathrm{L}$, while SD had the lowest in the 2017 season. In the second season, 2018, L had the highest concentration, at $90 \mathrm{mg}$ $\mathrm{N} / \mathrm{L}$, whereas $\mathrm{S}$ had the lowest, at $70 \mathrm{mg} \mathrm{N} / \mathrm{L}$, although this remained the same as in the previous year. Overall, the ammonia concentrations for 2018 increased from those of the previous year, with the exception of the S system.

It can be hypothesised that vintage effect could have played a role in this instance. The concentration of free amino acids varied between systems, with an average of $143 \mathrm{mg}$ N/L (B) and $207 \mathrm{mg} \mathrm{N} / \mathrm{L}$ (L) for 2017 and $200 \mathrm{mg} / \mathrm{N} / \mathrm{L}$ (S) and $260 \mathrm{mg} \mathrm{N} / \mathrm{L}$ (L) for 2018. Previously, from the point of view of canopy manipulation (shoot positioning, defoliation, topping and suckering), no variation was observed between the concentrations of FAN in the must of Chenin blanc from different seasonal practices (Volschenk \& Hunter, 2001). Other than that, there are no other reports on the effects of trellising systems on free amino nitrogen.

ANOVA showed statistical differences between the juices based on specific amino acids (Table 3 ). Amino acids (AA) can be grouped according to the order in which yeast (Saccharomyces spp.) metabolises them. The group of yeastpreferred amino acids consists of individual amino acids

TABLE 2

The yeast assimilable nitrogen (YAN), free amino nitrogen (FAN) and ammonia concentrations in the must.

\begin{tabular}{|c|c|c|c|c|c|c|}
\hline \multirow[t]{2}{*}{ Trellis } & \multicolumn{2}{|c|}{ FAN (mg N/L) } & \multicolumn{2}{|c|}{$\mathrm{NH}_{4}(\mathrm{mg} \mathrm{N} / \mathrm{L})$} & \multicolumn{2}{|c|}{ YAN (mg N/L) } \\
\hline & 2017 & 2018 & 2017 & 2018 & 2017 & 2018 \\
\hline $\mathbf{S}$ & 177 & 200 & 70 & 70 & 247 & 270 \\
\hline B & 143 & 230 & 50 & 80 & 193 & 310 \\
\hline SD & 133 & 240 & 40 & 80 & 173 & 320 \\
\hline TF & 173 & 250 & 50 & 80 & 223 & 330 \\
\hline $\mathbf{L}$ & 207 & 260 & 60 & 90 & 267 & 353 \\
\hline
\end{tabular}


TABLE 3

The concentration in $\mathrm{mg} \mathrm{N} / \mathrm{L}$ of the 20 amino acids measured in the musts of the six trellising systems in 2017. Significant differences $(\mathrm{p}<0.05)$ are designated by different letters.

\begin{tabular}{|c|c|c|c|c|c|}
\hline \multirow{2}{*}{$\frac{\text { Amino acid }}{\text { Yeast preferred }}$} & \multicolumn{5}{|c|}{ Trellis } \\
\hline & $\mathbf{S}$ & B & SD & TF & $\mathbf{L}$ \\
\hline Alanine & $96.2 b c$ & $79.3 \mathrm{c}$ & $77.4 \mathrm{c}$ & $113.5 b$ & $180.7 \mathrm{a}$ \\
\hline Arginine & $353.6 \mathrm{ab}$ & $285.2 b c$ & $242.7 \mathrm{c}$ & $305.0 \mathrm{bc}$ & $424.1 \mathrm{a}$ \\
\hline Aspartic acid & $101.2 \mathrm{a}$ & $66.2 \mathrm{bc}$ & $66.6 b c$ & $52.3 \mathrm{c}$ & $85.5 \mathrm{ab}$ \\
\hline Glutamic acid & $104.7 \mathrm{c}$ & $111.9 \mathrm{bc}$ & $112.8 \mathrm{bc}$ & $128.3 b$ & $169.3 \mathrm{a}$ \\
\hline Glutamine & $80.4 b$ & $60.8 \mathrm{c}$ & $48.9 \mathrm{c}$ & $76.4 b$ & $100.8 b$ \\
\hline Serine & $58.5 b$ & $57.6 \mathrm{~b}$ & $58.4 \mathrm{~b}$ & $77.9 \mathrm{a}$ & $85.3 \mathrm{a}$ \\
\hline \multicolumn{6}{|c|}{$\begin{array}{l}\text { Branched chain and } \\
\text { aromatic amino acids }\end{array}$} \\
\hline Valine & $24.6 \mathrm{~cd}$ & $29.3 b c$ & $22.2 \mathrm{~d}$ & $39.4 \mathrm{a}$ & $34.1 b$ \\
\hline Leucine & $26.9 b$ & $25.3 b$ & $21.1 b$ & $36.1 \mathrm{a}$ & $27.3 b$ \\
\hline Isoleucine & $12.5 b$ & $15.7 \mathrm{ab}$ & $12.1 b$ & $19.2 \mathrm{a}$ & $14.9 \mathrm{ab}$ \\
\hline Phenylalanine & $25.5 b$ & $36.5 \mathrm{ab}$ & $25.7 b$ & $43.3 \mathrm{a}$ & $32.6 \mathrm{ab}$ \\
\hline Tryptophan & $95.6 b$ & $132.6 \mathrm{ab}$ & $82.1 b$ & $188.8 \mathrm{a}$ & $101.2 \mathrm{~b}$ \\
\hline \multicolumn{6}{|l|}{ Others } \\
\hline Hydroxyproline & $2.4 \mathrm{~b}$ & $8.3 \mathrm{a}$ & $6.4 \mathrm{ab}$ & $8.3 \mathrm{a}$ & $9.4 \mathrm{a}$ \\
\hline Proline & $170.6 \mathrm{~d}$ & $297.5 \mathrm{c}$ & $306.6 \mathrm{c}$ & $534.1 \mathrm{~b}$ & $676.4 \mathrm{a}$ \\
\hline Methionine & $1.0 \mathrm{a}$ & $1.3 \mathrm{a}$ & $0.1 \mathrm{a}$ & $1.7 \mathrm{a}$ & $0.1 \mathrm{a}$ \\
\hline Lysine & $2.6 \mathrm{a}$ & $3.0 \mathrm{a}$ & $2.7 \mathrm{a}$ & $4.0 \mathrm{a}$ & $4.1 \mathrm{a}$ \\
\hline Threonine & $101.3 \mathrm{~b}$ & $112.9 \mathrm{ab}$ & $95.3 b$ & $121.5 \mathrm{a}$ & $124.6 \mathrm{a}$ \\
\hline Glycine & $2.5 \mathrm{a}$ & $3.1 \mathrm{a}$ & $2.8 \mathrm{a}$ & $3.8 \mathrm{a}$ & $4.3 \mathrm{a}$ \\
\hline Histidine & $32.9 \mathrm{a}$ & $22.2 b$ & $22.2 b$ & $30.4 a$ & $31.0 \mathrm{a}$ \\
\hline Ornithine & $1.9 \mathrm{a}$ & $0.3 b$ & $0.0 \mathrm{~b}$ & $0.4 b$ & $1.9 \mathrm{a}$ \\
\hline GABA & $34.8 \mathrm{c}$ & $38.8 \mathrm{c}$ & $48.9 \mathrm{bc}$ & $64.9 \mathrm{ab}$ & $70.5 \mathrm{a}$ \\
\hline
\end{tabular}

such as alanine (ALA), arginine (ARG), aspartic acid (ASP), glutamic acid (GLU), glutamine (GLN) and serine (SER) (Ljungdahl \& Daignan Fornier, 2012). This group was found to have the highest concentration in the L system must, with glutamic acid, glutamine and alanine significantly higher than in the other systems.

Another subgroup of AA is branched chain and aromatic amino acids (BCAAs, valine(VAL), leucine(LEU), isoleucine (ILE), phenylalanine (PHE) and tryptophan (TRP)). These amino acids play an important role as precursors of certain aroma compounds (Bell \& Henschke, 2005). The TF trellis produced juices with a significantly higher concentration of valine and leucine, and they were also higher in the other three BCAAs, although not significantly so, whereas the SD trellis was found to have the lowest concentration of BCCAs.

The data shown in Table 3 illustrates that concentrations of the secondary amino acids proline (PRO) and hydroxyproline (HYP) were significantly higher in the musts of the L system (676 mg N/L), while S had the lowest concentrations (170 mg N/L). Even if the concentration of proline is the highest among amino acids, secondary AA are usually not metabolised by yeast. However, proline is seen as an indicator of stress in the vineyard, as found by Ashraf and Foolad (2007). A similar trend is seen in other amino acids (GABA, ornithine (ORN), and threonine (THR)). Notably, the juices from the $\mathrm{S}$ system were significantly higher only in histidine (HIS), while the SD and B systems were recorded to have the lowest average value.

The PCA generated using the AA concentrations (Fig. 2, PC1 39.4\% and PC2 21.2\%, respectively) showed that the samples belonging to one system tended to group together, but samples from different systems were also interposed, as demonstrated by cluster analysis.

Amino acid concentration varies according to cultivar (Kliewer, 1970); it is also known that trellis type can influence grape amino acid composition and concentration through differences in either bunch or leaf exposure to light (Kliewer et al., 1991). In the present study, it can be 


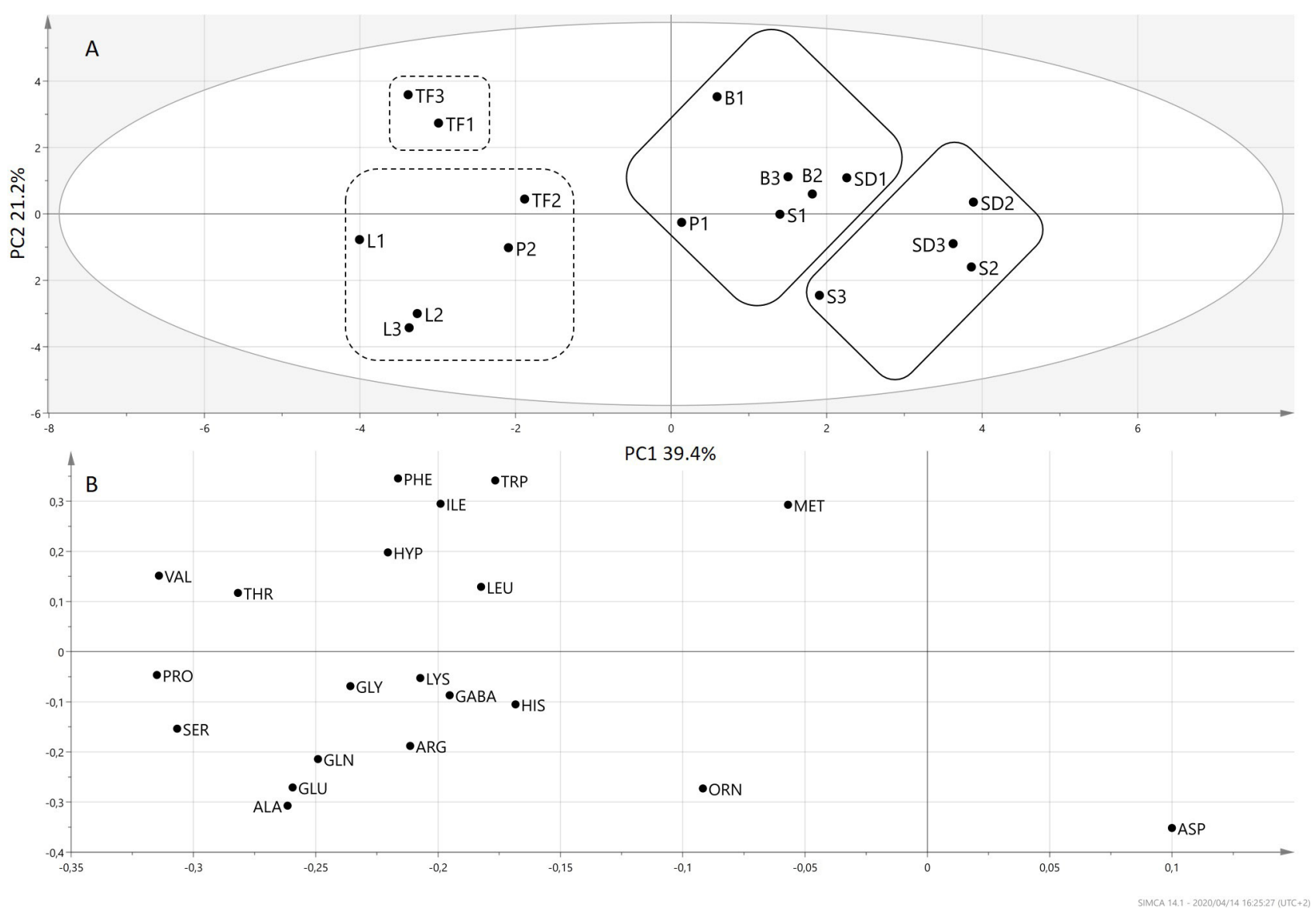

FIGURE 2

Plots of principal component analysis scores (top) and loadings (bottom) for the amino acid composition of the 2017 must. Grayscale in the scores plot codes according to trellis system. The groupings in the scores plot are designated according to the hierarchical cluster analysis (HCA) of the same data, and the different/similar outlines indicate level of distances between groups based on the HCA dendrogram

speculated that a particular trellis also resulted in specific leaf and bunch exposure, which possibly influenced the concentration of individual amino acids. Looking at the similarities in multivariate and ANOVA, it could mean that the effect of the trellising on the concentration of amino acids played a consistent role only in the $\mathrm{L}$ and $\mathrm{S}$ systems. Pereira et al. (2006) found higher amino acid concentrations in the juice of unshaded berries of Merlot compared to shaded berries. Other studies (Friedel et al., 2015) have also provided evidence that sun exposure through leaf and bunch removal increases the amino acids of Riesling grapes. However, the variety itself could play a role in its response to factors such as light; for example, Gregan et al. (2012) found a reduction in total amino acids in berries exposed to sunlight in Sauvignon blanc. However, other studies, such as that of Šuklje et al. (2016), have confirmed that the differences in amino acid concentration were also due to the different clones' responses to bunch exposure. As mentioned earlier, TF musts specifically were significantly higher in BCAAs. TF trellises have open canopies, which may result in the berries being exposed to better light interception, consequently affecting amino acid metabolism. Similarly, Pereira et al. (2006) also found a higher level of BCAAs (valine and leucine) in sun-exposed berries of Merlot.

\section{Aroma composition}

A total of 25 major volatile compounds were identified and quantified in the Chenin blanc wines using GC-FID; for discussion, they have been classified into five groups: esters, acetates, ethyl esters, acids and alcohols, according to their functional groups and metabolic formation (Tables 4A and 4B). Even though differences were found between the systems for the individual compounds and classes of the major volatiles, none of them were statistically significant. Another class of odour compounds measured were thiols (Tables 4A and 4B). Again, the samples did not differ significantly in 2017; ANOVA indicated significant differences between the systems for 3MHA in 2018, but only for the highest concentration (Table 4B).

PCA was performed using all the data on the 2017 volatiles (major volatiles and thiols, PC1 37.9\% and PC2 $18.8 \%$, respectively), to see if there was any grouping based on these compounds (Fig. 3 top). PCA showed a pattern in which the $\mathrm{P}$ and $\mathrm{L}$ samples were grouped together (with two of the TF samples), separate from the rest of the system samples along PC1. Furthermore, the loading plots (Fig. 3 bottom) showed no discriminant factor to produce clearer groupings based on the HCA results. As shown by ANOVA, the two treatments were the highest in total volatiles 
(Table 4A).

PCA was also performed on the volatiles using major volatile compounds and thiol concentrations for 2018 (results not shown). No separation of wines was observed according to the treatment (PC1 31.6\% and PC2 24.7\%, respectively) Despite the significant differences for $3 \mathrm{MHA}$ in the $\mathrm{L}$ wines, this was not a strong enough discriminant factor to separate these samples in the PCA. Similarly, the cluster analysis and loadings showed no specific compound to be highly associated with specific wines or groupings based on trellising system.

Aroma compounds come from either grapes, the fermentation processes or ageing. Those derived from grapes are likely to be influenced by environmental conditions, including as a result of training system (Zoecklein et al., 2008). Most importantly, light or sunlight exposure is one of the factors that affect the accumulation and synthesis of aroma-related compounds (Ford, 2007). From previous work, it can be seen that UV-C light irradiation amplifies the thiol precursors (Kobayashi et al., 2011); however, it is not fully understood how there is a correlation between thiol precursors and wine thiols. Parish-Virtue et al. (2019) reported a positive response of light on Sauvignon Blanc from grapes to the corresponding wines.

It is hypothesised from the literature that a similar design exposes the fruit zone to light intensity and influences the type and level of chemical compounds synthesised, consequently affecting the aroma profile (Šuklje et al., 2016). This only applies to compounds directly affected by sun exposure, in this case thiols. Light (for example driven by trellising systems) may have induced variations in the concentration of 3MHA. However, this effect may be revised in the case of the current study, because 3MHA was not detected in the wines from the L system in the first season.

Looking at other treatments, there was an increase in the concentration of 3MHA from the first season to the second, which is similar to the findings of Drenjančević et al. (2018) and Louw et al. (2010), who demonstrated that vintage is the

TABLE 4A

Concentrations of major volatiles $(\mu \mathrm{g} / \mathrm{L})$ and thiol compounds $(\mathrm{ng} / \mathrm{L})$ in wines made from the six trellising systems $(2017$ vintage). 4MMP was not detected in the 2017 wines. Significant differences indicated by different letters.

\begin{tabular}{lcccccc}
\hline Compounds & $\mathbf{S}$ & $\mathbf{B}$ & $\mathbf{S D}$ & $\mathbf{T F}$ & $\mathbf{L}$ & $\mathbf{P}$ \\
\hline Ethyl acetate & 29.17 & 36.45 & 41.52 & 48.86 & 68.31 & 48.97 \\
Ethyl lactate & 6.19 & 4.86 & 5.15 & 3.74 & 4.64 & 3.74 \\
Ethyl caprylate & 1.61 & 1.46 & 1.16 & 1.28 & 1.60 & 1.16 \\
Ethyl caprate & 1.67 & 1.42 & 1.37 & 1.54 & 2.0 & 1.95 \\
Ethyl phenylacetate & 1.03 & 1.07 & 1.18 & 1.36 & 1.40 & 1.67 \\
Ethyl hexanoate & 6.80 & 6.80 & 9.46 & 6.63 & 1.08 & 9.50 \\
2-Phenylethyl acetate & 4.88 & 4.26 & 3.38 & 3.59 & 4.05 & 3.41 \\
Diethyl succinate & 2.62 & 2.94 & 2.59 & 3.06 & 3.21 & 3.08 \\
Isoamyl acetate & 5.13 & 5.27 & 4.88 & 5.18 & 6.05 & 5.28 \\
Isobutanol & 21.91 & 19.90 & 25.86 & 31.29 & 32.59 & 35.60 \\
Pentanol & 5.74 & 6.10 & 5.74 & 7.57 & 7.45 & 6.29 \\
Isoamyl alcohol & 170.12 & 157.27 & 183.06 & 173.88 & 176.49 & 204.26 \\
Hexanol & 1.40 & 4.01 & 6.73 & 5.94 & 8.22 & 6.94 \\
Butanol & 4.34 & 7.40 & 8.12 & 4.11 & 1.60 & 1.21 \\
Propanol & 21.25 & 18.67 & 18.75 & 30.80 & 52.47 & 33.64 \\
2-Phenyl ethanol & 4.08 & 3.83 & 3.13 & 2.38 & $1.78 \mathrm{a}$ & 2.04 \\
Propionic acid & 1.37 & 1.49 & 1.73 & 2.23 & 2.62 & 2.29 \\
Isobutyric acid & 1.59 & 1.15 & 1.45 & 1.46 & 1.70 & 2.25 \\
Butyric acid & 1.61 & 1.16 & 1.39 & 3.97 & 1.32 & 2.05 \\
Isovaleric acid & 5.79 & 3.91 & 1.24 & 1.40 & 1.55 & 1.47 \\
Valeric acid & 5.84 & 5.34 & 5.98 & 1.65 & 2.35 & $2.05 \mathrm{a}$ \\
Hexanoic acid & 24.36 & 25.33 & 19.55 & 26.55 & 22.17 & 31.6 \\
Octanoic acid & 4.69 & 6.14 & 6.70 & 5.42 & 5.61 & 5.13 \\
Decanoic acid & 4.69 & 6.14 & 6.70 & 5.42 & 5.61 & 5.13 \\
\hline
\end{tabular}


TABLE 4A (CONTINUED)

\begin{tabular}{lcccccc}
\hline Compounds & S & B & SD & TF & L & P \\
\hline Major volatile groups & & & & & & \\
\hline Total volatiles & 341.22 & 337.52 & 371.66 & 381.13 & 421.60 & 425.84 \\
Esters & 62.46 & 69.69 & 75.53 & 77.06 & 98.06 & 83.86 \\
Acetates & $39.18 \mathrm{a}$ & 45.98 & 49.78 & 57.63 & 78.41 & 57.66 \\
Ethyl esters & 52.45 & 60.16 & 67.27 & 68.29 & 87.96 & 75.17 \\
Acids & 49.94 & 50.65 & 44.75 & 48.11 & 42.93 & 52.01 \\
Alcohols & 228.82 & 217.18 & 251.38 & 255.96 & 280.61 & 289.97 \\
\hline Thiols & & & & & & \\
\hline 3MH & 150 & 354 & 112 & 340 & 16 & n.q. \\
3MHA & 0.2 & 34 & 17.6 & & 1.52 \\
\hline
\end{tabular}

n.q. - not quantified

TABLE 4B

Concentrations of major volatiles $(\mu \mathrm{g} / \mathrm{L})$ and thiol compounds $(\mathrm{ng} / \mathrm{L})$ in wines made from the six trellising systems $(2018$ vintage). Significant differences indicated by different letters.

\begin{tabular}{|c|c|c|c|c|c|}
\hline Compounds & $\mathbf{S}$ & B & SD & TF & $\mathbf{L}$ \\
\hline Ethyl acetate & 57.24 & 84.78 & 69.19 & 78.22 & 81.30 \\
\hline Ethyl lactate & 3.35 & 9.13 & 2.01 & 2.15 & 2.24 \\
\hline Ethyl caprylate & 2.28 & 2.40 & 1.97 & 2.05 & 2.19 \\
\hline Ethyl caprate & 3.25 & 3.84 & 3.69 & 3.83 & 4.00 \\
\hline Ethyl phenelthylacetate & 1.27 & 1.34 & 1.50 & 1.33 & 1.39 \\
\hline Ethyl hexanoate & 1.14 & 1.15 & 1.13 & 1.15 & 1.17 \\
\hline 2-Phenylethyl acetate & 5.00 & 6.95 & 4.43 & 5.51 & 5.03 \\
\hline Diethyl succinate & 4.14 & 2.22 & 3.69 & 3.85 & 3.13 \\
\hline Isoamyl acetate & 6.17 & 7.95 & 6.70 & 7.98 & 8.32 \\
\hline Isobutanol & 31.18 & 40.71 & 34.85 & 34.95 & 32.04 \\
\hline Pentanol & 8.63 & 1.15 & 1.02 & 4.01 & 8.97 \\
\hline Isoamyl alcohol & 203.93 & 219.43 & 211.97 & 203.56 & 209.54 \\
\hline Hexanol & 8.82 & 7.55 & 7.86 & 7.52 & 7.31 \\
\hline Butanol & 7.09 & 1.13 & 3.82 & 3.76 & 4.01 \\
\hline Propanol & 42.43 & 63.96 & 63.95 & 71.20 & 79.47 \\
\hline 2-Phenyl ethanol & 35.26 & 38.96 & 28.55 & 26.58 & 22.88 \\
\hline Propionic acid & 2.07 & 2.94 & 2.88 & 2.64 & 2.90 \\
\hline Isobutyric acid & 1.69 & 1.86 & 1.65 & 1.66 & 1.57 \\
\hline Butyric acid & 1.33 & 1.48 & 1.37 & 1.33 & 1.42 \\
\hline Iso-valeric acid & 2.37 & 4.01 & 3.65 & 6.42 & 8.95 \\
\hline Valeric acid & 3.30 & 3.62 & 3.58 & 4.05 & 3.47 \\
\hline Hexanoic acid & 3.29 & 4.35 & 3.93 & 4.29 & 4.50 \\
\hline Octanoic acid & 4.12 & 4.17 & 3.91 & 4.36 & 4.62 \\
\hline Decanoic acid & 8.82 & 8.96 & 8.63 & 1.02 & 3.58 \\
\hline
\end{tabular}




\begin{tabular}{lccccc}
\hline Major volatile groups & & & & & \\
Total volatiles & 454.06 & 530.23 & 480.81 & 489.98 & 510.53 \\
Esters & 89.72 & 125.95 & 99.20 & 112.63 & 115.31 \\
Acetates & 68.40 & 99.68 & 80.31 & 91.71 & 94.64 \\
Ethyl esters & 78.56 & 111.05 & 88.08 & 99.14 & 101.97 \\
Acids & 26.99 & 31.39 & 29.60 & 25.78 & 31.00 \\
Alcohols & 337.34 & 372.89 & 352.01 & 351.58 & 364.22 \\
\hline Thiols & & & & & \\
\hline 3MH & 334 & 390 & 307 & 298 & 292 \\
3MHA & $37.2 \mathrm{~b}$ & $38.4 \mathrm{~b}$ & $29.5 \mathrm{~b}$ & $37.3 \mathrm{~b}$ & $63.4 \mathrm{a}$ \\
4MMP & 2.41 & 2.50 & 2.54 & 2.38 & 2.56 \\
\hline
\end{tabular}
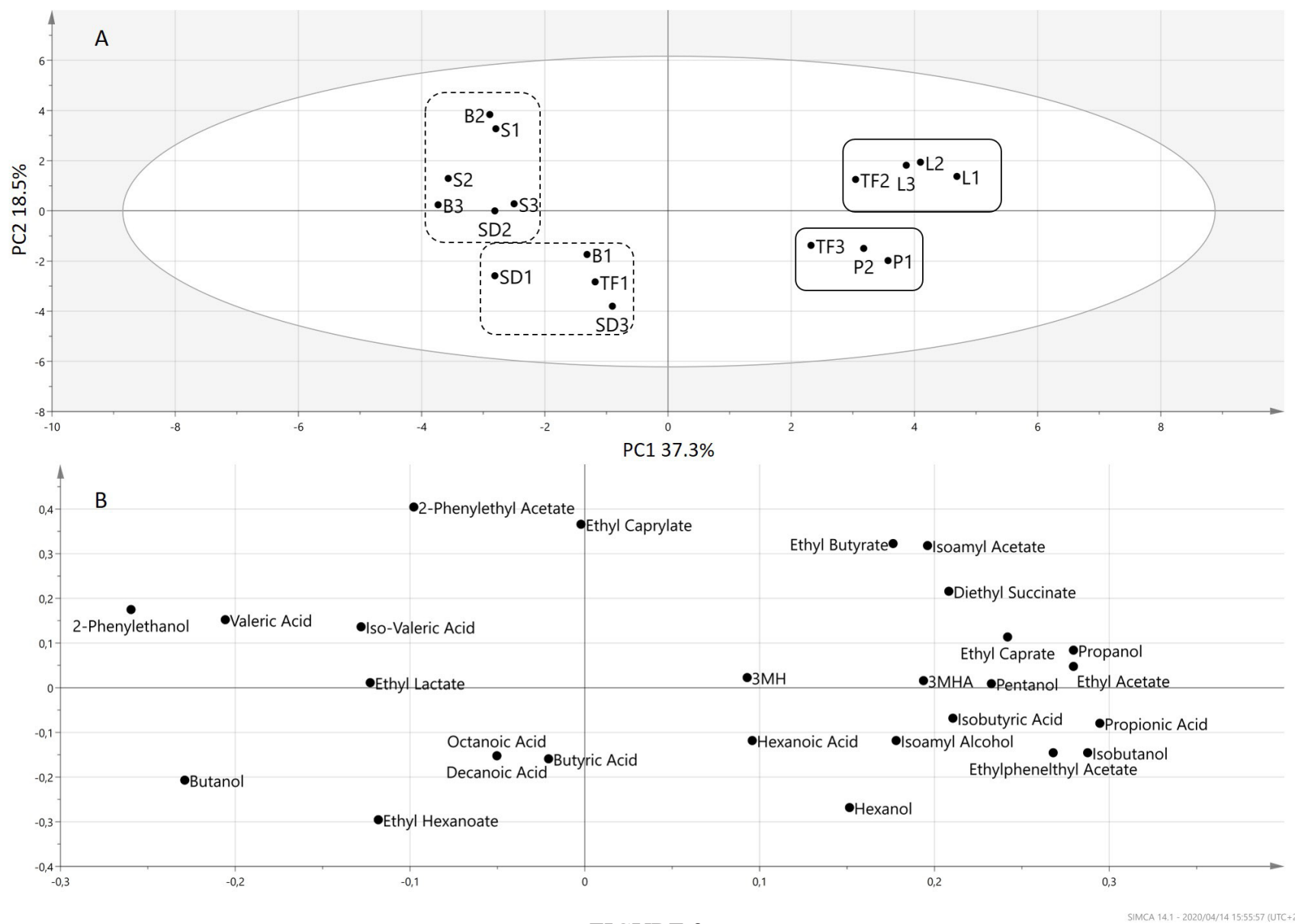

FIGURE 3

Principal component analysis scores (top) and loading plots (bottom) for the major volatile and thiol data from wines from the 2017 vintage. Grayscale in the score plot codes according to trellis system. The groupings in the score plot are designated according to hierarchical cluster analysis (HCA) of the same data, and the different/similar outlines indicate level of distances between groups based on the HCA dendrogram

source of variation in the volatile composition of Cabernet Sauvignon, Sauvignon blanc, Chardonnay, Pinotage, Merlot and Shiraz wines. Microclimatic conditions were not measured in the current study but, based on previous research, moderate cluster exposure to sunlight increases flavour compounds in Traminette grapes ( $\mathrm{Ji} \&$ Dami, 2008). Common compounds that are documented as being influenced by light are the $\mathrm{C}_{6}$ compounds (Zoecklein et al., 
2008), and these are among the potential precursors involved in 3MH and 3MHA formation (Harsch et al., 2013).

Marais et al. (1981) found a correlation between amino acids in the must and ester formation. Because of this phenomenon, the hypothesis would be that a significant difference in certain amino acids in the must should correspond to a significant difference in the resulting esters' concentrations in the wine. For the major volatiles, as derived from AA metabolism, a configuration similar to the AA results was found, with the L, P and TF samples grouped together in both cases (Figs 4 and 5).

In addition, some trellising systems, such as Lyre, optimise leaf surface area, which may lead to the optimisation of sunlight use. It is possible that other chemical compounds like terpenes were influenced in the current study. Marais (1983) generated data that suggests that Chenin blanc leaves are rich in terpenes, and Lawrence (2012) and Bruwer (2018) later confirmed the presence of monoterpenes in wines.

Therefore, there is a chance that compounds other than major volatiles and thiols (viz. terpenes) may have contributed to the aroma profile of the wines because it has been demonstrated that sunlight influences the concentration of terpenes in wine (Marais et al., 1992). The manner in which the canopies in the L system are opened up permits good interception of light, which improves fruit exposure and may lead to an increase in the concentrations of thiol precursors in the berries. It has been confirmed that there is an increase in the Gluy-3SH level in the grapes and must of Sauvignon blanc as a result of the effect of nitrogen status on 3MH content (Helwi et al., 2016). A study by Lloyd (2013) reported the enhancement of green characters in Sauvignon blanc wines as a result of changes in light exposure.

\section{Untargeted analyses}

The untargeted LC-HRMS analysis was used to evaluate the effect of trellising systems on the chemical characteristics of the corresponding wines. PCA was used to explore the samples' grouping according to the positive and negative ionisation dataset generated for the two seasons (2017 and 2018, Fig. 4).

Interestingly, the separation corresponded with the taste and mouthfeel profile trend in the sensory results. The hypothesis could be that some compounds (for example polyphenols that give an MS signal in the negative ionisation mode) have been affected similarly by certain types of trellising. Polyphenols make a relevant contribution to
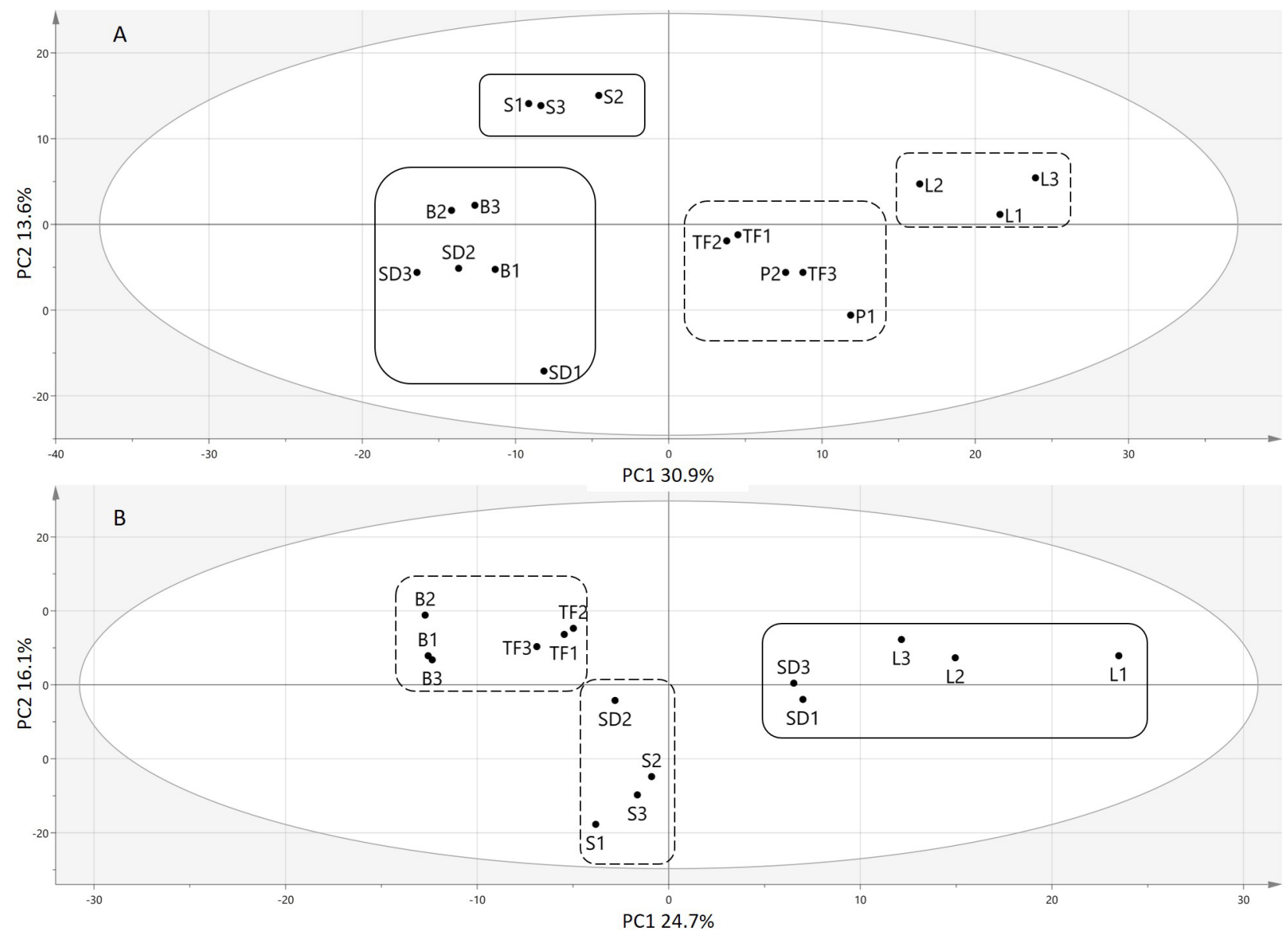

FIGURE 4

Plot of principal component analysis scores and the hierarchical cluster analysis dendrogram for the high resolution-mass spectrometry data for the 2017 (top) and 2018 (bottom) vintage wines. Grayscale in the score plot codes according to trellis system. The groupings in the score plot are designated according to the hierarchical cluster analysis (HCA) of the same data, and the different/similar outlines indicate distances between groups based on the HCA dendrogram 
sensorial properties such as taste and mouthfeel (Gawel et al., 2018).

The results from the two vintages illustrate that trellising systems have an effect on the chemical composition of wines, mostly on compounds responsible for the taste and mouthfeel of wine. Although this study could not identify the compounds responsible for the configuration due to the untargeted nature of the analysis, they are the factor that leads to the grouping according to trellising systems. Phenolics are responsible for the taste and texture characters in wine in interaction with other components, are influenced by practices in the vineyard, and there is a correlation between phenolics and sunlight (Šebela et al., 2017). Because the differentiation of wines according to trellising systems by fingerprint is based largely on phenolics, it can be hypothesised that sunlight exposure played a role in the samples' configuration.

Considering the canopy structure, SD and B systems are parent and variant of each other, therefore the exposure of their foliage and/or berries to sunlight would be comparable. As a result, they could produce wines with analogous fingerprints, as seen in the close placement on the PCA score plots (Fig. 4). Following the same reasoning, TF and L systems with open horizontal canopies would result in a similar light distribution and interception by the berries, hence the corresponding wines were positioned next to each other on the PCA score plots (Fig. 4). Santorini architecture places the grape berries in the shade, and for each season this system produced wines with a different fingerprint from the other systems. To date, no published work has evaluated the LC-HRMS profile of wines made from different trellising systems to be able to compare to the results of this study.

\section{Results of sensory evaluation \\ Aroma profile of Chenin blanc wines}

For the 2017 expert panel, the biplot obtained from the CATA results showed an overlapping trend for a set of wines from different trellising systems along dimension 1 (Dim 1) and dimension 2 (Dim 2), which explained 33.8\% and $26.0 \%$ of the variance, respectively, and totalling $59.8 \%$ (Fig. 5). All wines were grouped, except for the wines from the L system. The raw data (frequency of citation) from experts in the first season (2017) shows that the most used attribute overall was 'passion fruit'. This attribute also had the highest citation frequency for the wine from the $\mathrm{L}$ system. Overall, it appears that the differences were small with regard to the number of terms used per treatment to characterise the wines. To further investigate the individual attributes used, compiling a 'top five' and a 'top ten' list based on frequency counts helped explain the groupings of the correspondence analysis. According to these lists, the term 'pineapple' was used frequently across all treatments, while 'lemon' 'melon' and 'peach' appeared in four to five treatments. 'Honeysuckle' and 'hay'/'straw' also appeared in the top five frequently cited notes associated with SD and $\mathrm{TF}$, respectively, as unique features compared with the rest. In spite of the unique features in some treatments, it is suggested that there was no significant impact on odour threshold perception, as there was no clear separation between samples. The overall visualisation shows that all treatments had a common fermentative origin, as 'fruity' and 'floral', and no discriminant attribute or compound was identified.

L system wines were characterised by 'grapefruit' and 'passion fruit' descriptors, which are typically associated with 3MHA, which is formed by the esterification of $3 \mathrm{MH}$ with acetic acid during fermentation (Tominaga et al., 1998). 3MHA levels were the highest in the first season, and were significantly higher in the L system wines compared to the rest of the systems, as seen from the chemical results of this study (Table 4A). The architecture of the L systems opens up for good light interception and enhances fruit exposure, which might have led to increased concentrations of precursors of this class of aroma compounds. This can be correlated with ripening at harvest induced by light exposure (Lloyd, 2013).

Also, non-volatile precursors found in the berries and the must can be increased. Helwi et al. (2016) found an increase in Gluy-3SH levels in the grapes berries and must of Sauvignon blanc as a result of a positive effect of nitrogen status on $3 \mathrm{MH}$ content. Additionally, L wines were significantly higher in yeast-preferred amino acids, namely glutamine and alanine, the same trend seen with FAN, which plays a vital role in ester production (Tables 2 and 3 ), although the difference was not reflected in the aroma descriptors of the resulting wines.

Unlike the experts, the analytical panel used the term 'pineapple' frequently and across all treatments. In addition, 'passion fruit' was common in all the sample wine treatments, and 'guava' and 'lemon' appeared in the top five notes in four out of five treatments. Another attribute that was prominent was 'grapefruit'; although cited the least compared to the other top five notes, it appeared in all six treatments. Similarly to the experts, the analytical panel characterised all wines with 'fruity' and 'floral' attributes, in addition to certain attributes that were associated with particular treatments, although these did not contribute significantly. An indication of similarities between the wines' perceived aroma could already be based on this raw data and was confirmed by multivariate analysis (Fig. 5B). Correspondence analysis obtained from the analytical panel for the same 2017 vintage using the CATA results shows a total of $48.4 \%$ explained variance for the first two dimensions (Fig. 5B).

Even though the grouping was similar by the analytical panel and the experts, and the panels used the same CATA list, the two panels described the wines differently. The experts profiled wines from the L systems as 'baked bread', 'vanilla' and 'stewed fruits', whereas the analytical panel perceived them as having 'oak' and 'fynbos' characters. Despite the terminology used by the two types of panels being different - which is to be expected given the nature of their background knowledge - both groups of descriptors implied a certain degree of 'toasted', 'woody' and 'sweet associated' characters.

In the second season, the most frequently cited term was 'pineapple'. Unlike in the previous season, this attribute was highly associated with the L system; however, it was present in all treatments. Other terms that were frequently cited were 'passion fruit', 'apple' and 'orange'. Moreover, 'lemon' was commonly used in all treatments as part of the top ten most- 

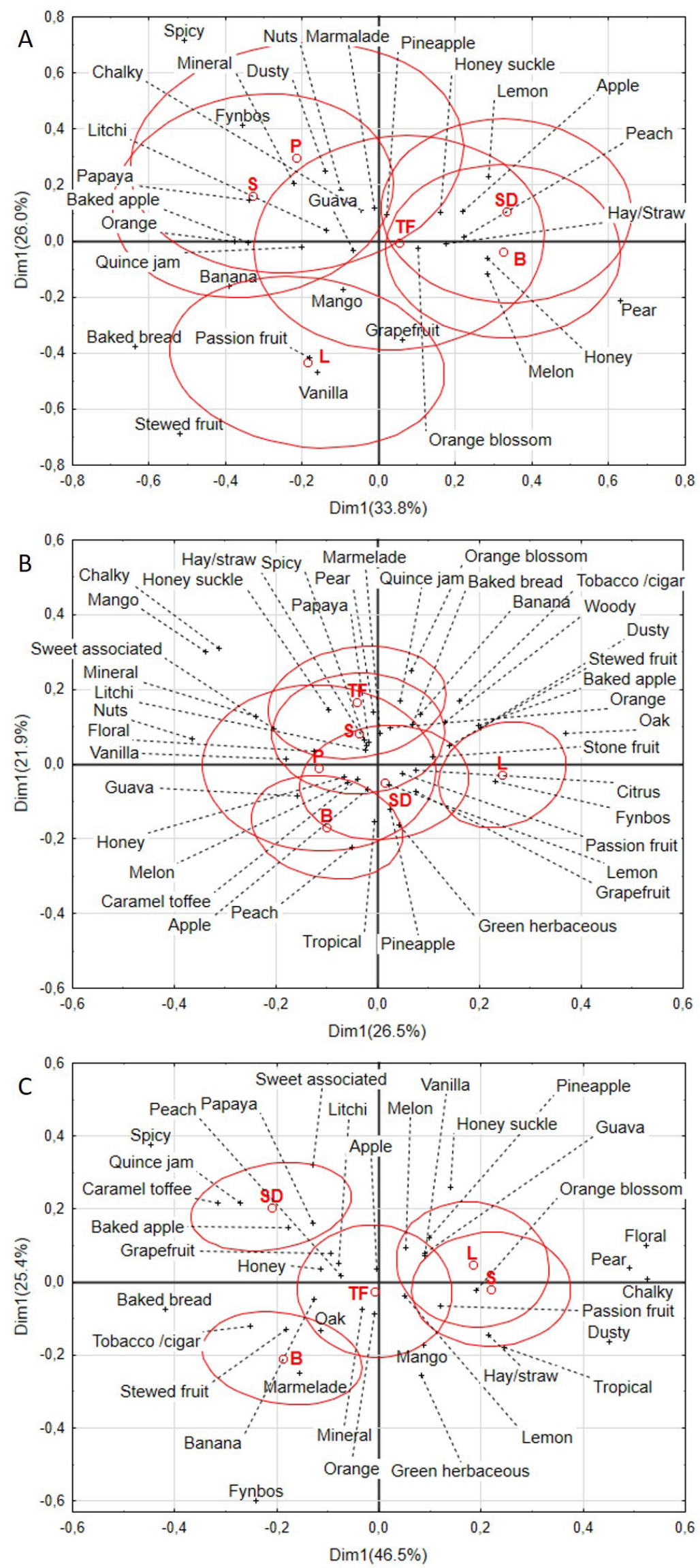

FIGURE 5

Correspondence analysis biplot for the results of the aroma evaluation for: A. 2017 expert panel ( $\mathrm{n}=30$ judges, 30 answers); B. 2017 analytical panel ( $\mathrm{n}=10$ judges, 30 answers); and C. 2018 analytical panel ( $\mathrm{n}=10$ judges, 30 answers). Ellipses indicate $95 \%$ confidence 
used terms, and 'peach' was the least-used attribute among the top ten. Overall, three of the top five attributes used were the same ('pineapple', 'apple' and 'passion fruit') in both vintages across all treatments.

Furthermore, a similar trend was observed in the panels regarding the raw data from 2017 and 2018, namely that all wines were described as having 'fruity', 'guava', and 'floral' notes, which relate to esters, thiols and possibly other aromatic chemical compounds (terpenes) not analysed in the current study.

The 2018 vintage aroma profiles in the bi-plot obtained from correspondence analysis of the CATA data showed a better separation than in the previous vintage (Fig. 5C). The separation is derived from Dim 2, which captured $25.4 \%$, while Dim 1 captured $46.5 \%$ of the explained variance, totalling $71.9 \%$ of the explained variance.

The attributes associated with the groups that were formed could be linked to the volatile and non-volatile composition of must and wine. The descriptors for wines from the SD system, namely 'caramel' and 'sweet associated', may be linked with the sugar level at harvest, which was higher than in any of the other systems. Equally important, the sugar content of grape juice influences the alcohol content of the wine, which is known to impart a sweet flavour to wine (Peynaud \& Blouin, 1996). In 2018, the berries from the SD system were exposed to sunlight, which led to sunburn in most of the berry bunches. Furthermore, Marais et al. (1992) found faster sugar accumulation in sun-exposed grapes than in shaded grapes. This could have further affected the flavour of the resultant wines based on the aroma profile.

\section{Taste and mouthfeel of Chenin blanc wines}

The CA results of the evaluation of the taste and mouthfeel of the 2017 vintage wines by experts explained $92.5 \%$ of the total variance among the wines samples, with the first dimension mainly responsible for the separation, with $84.6 \%$ (Fig. 6A). The first dimension shows the trend among wines based on the body, projecting, from left to right, a separation from full body to medium through to light body. The TF, $\mathrm{L}$ and $\mathrm{P}$ wines were associated with the 'full body' and the 'long aftertaste driven by alcohol'. The SD and B wines were associated with the 'medium body', with the 'medium aftertaste' driven by 'bitterness' and 'flavours'. The S system wines were associated with the 'unbalanced light body', with a 'short aftertaste' that was driven by 'acidity'.

The taste and mouthfeel profiles obtained from the analytical panel data and that of the experts showed a similar trend and configuration (Fig. 6B). However, there is a visible separation between wines in the analytical panel data, notably forming three groups: wines from the TF, L and P systems (complex wines, 'full body', and 'long aftertaste' driven by 'alcohol' and 'flavour'), wines from the B and SD systems ('medium body', 'medium aftertaste'), and wines from the S system ('light body', 'short aftertaste' driven by 'acidity').

The biplot obtained from the analytical panel data for the taste and mouthfeel in 2018 showed a trend along Dim 1, which explained $60.5 \%$ of the variance, whereas Dim 2 explained $31.1 \%$ of the variance (Fig. 6C). The body and aftertaste influenced the pattern of wines described by 'complex full body'-'alcohol'-'flavour'-'balanced', through to 'medium body'-'medium aftertaste', and to 'water light body'-'unbalance'-'acidy', which were discriminated in Dim 2. Wines from the $\mathrm{L}$ and TF systems were described by 'full body' and 'long aftertaste', although the aftertaste of the TF wine was driven by 'alcohol' while L was driven by 'flavour'. Wines from the SD system were associated with 'medium body', 'medium aftertaste', and were driven by 'acidity' and 'flavour'. B system wines were described by 'medium body', 'medium complexity', 'unbalance' and 'bitterness'. The S system wines were characterised by 'short aftertaste', 'light body', and 'watery', with the latter attribute potentially linked to the sugar level at harvest, which was significantly lower than that of any other system and resulted in a lower percentage of alcohol (Table 1).

The raw data already made reference to the $\mathrm{S}$ treatment being associated predominantly with negative attributes like 'acidity', 'water', 'light body' and 'unbalance', possibly related to the shaded bunches. Multivariate analysis then confirmed the trend of S being separated from the rest of the samples in both vintages. Other samples could not clearly be ascribed simply by looking at the raw data; however, multivariate analysis was able to separate them. The TF treatment, perceived to have a taste driven by flavour, could be linked to the optimal interception of light by the system, as well as the alcohol percentage, which was higher than for the other systems.

Grape berries exposed to sunlight are generally higher in sugars and phenolic compounds compared to shaded berries (Morrison \& Noble, 1990). The systems with open canopies and canopies that allow sunlight exposure (TF, $\mathrm{L}$ and $\mathrm{P}$ ) are expected to produce wines higher in sugars, therefore full-bodied wines. Not all wines are expected to be big, full-bodied wines. However, they should present a pleasing entry into the palate and finish. The three aspects in wines, namely balance, body and astringency, are categories that are always in the consumer's mind when consuming wine. Good balance in wine complements the aroma, and highly acidic wines tend to be thin and watery with a dry perception (Conde et al., 2007). It is possible that the wines produced from the S system may be acidic due to the canopy architecture, which caused the berries to be in the shade. The contribution of sugars can counteract the acidity and build body in a wine. The S system's wines started with the lowest sugar, therefore there was nothing to counteract the acidity.

As part of canopy management, the temperature around the canopy could be the cause of a lower sugar level and consequently affect the organoleptic properties of wines from the $\mathrm{S}$ system. Other wines, such as those from the B and SD systems, produced similar wines with the same taste and mouthfeel, and again the design could play a role here because these two systems are similar (the B system being a variant of the SD system). Also, the TF and L systems are quite similar (vertical divided canopies). The wines from these systems had desirable characters, such as a 'long aftertaste' and an 'aftertaste driven by flavour', and had a 'full body'. Opening the canopy makes room for good light interception and also prevents sunburn and controls sugar levels. 

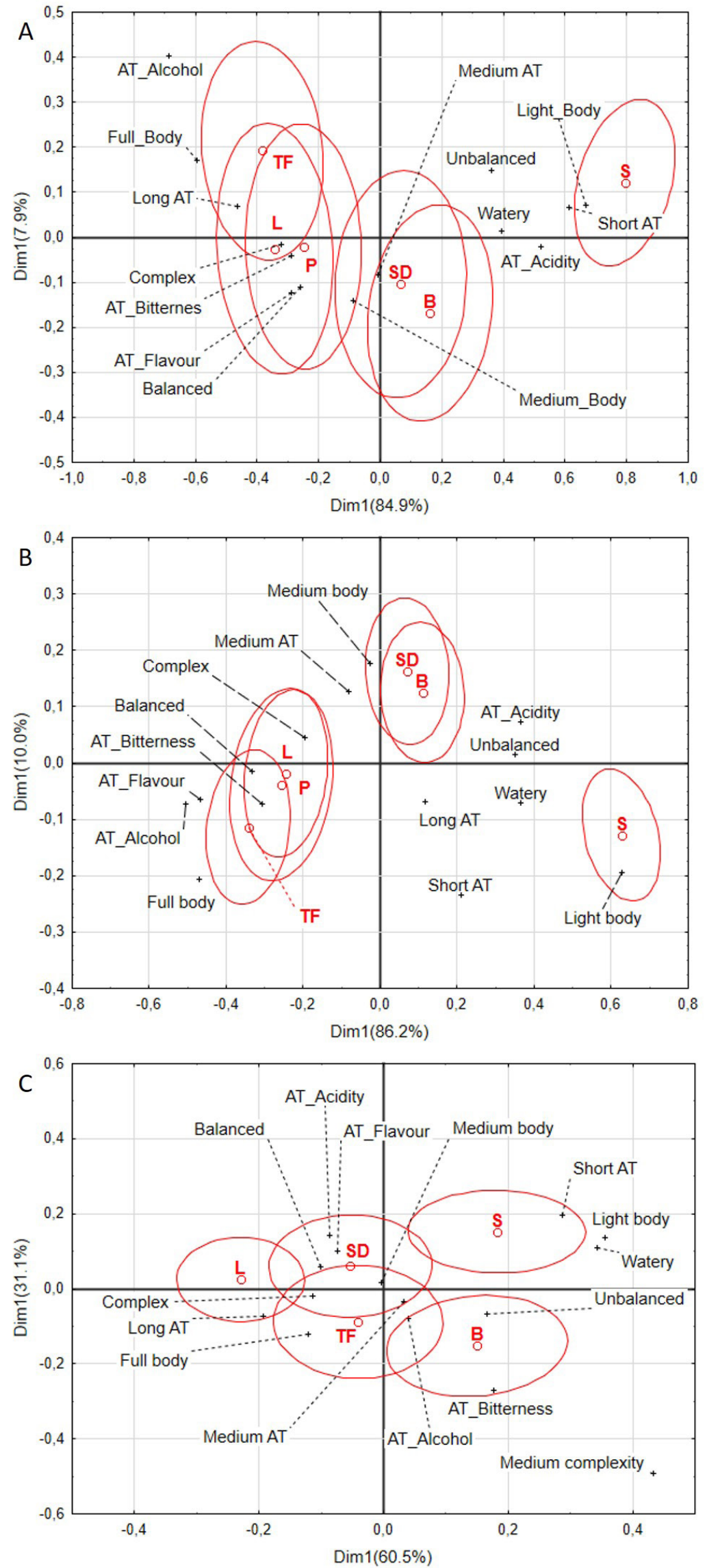

FIGURE 6

Correspondence analysis biplot of the results from the taste and mouthfeel evaluation for: A. 2017 expert panel ( $\mathrm{n}=30$ judges, 30 answers); B. 2017 analytical panel ( $\mathrm{n}=10$ judges, 30 answers); and C. 2018 analytical panel ( $\mathrm{n}=10$ judges, 30 answers). Ellipses indicate $95 \%$ confidence. 


\section{Overall quality assessment}

Differences between the wines based on appearance, aroma, taste and overall quality were obtained from one-way ANOVA results at $\mathrm{p}<0.05$ (results not shown). Among the sets, the $\mathrm{TF}$ and $\mathrm{L}$ wines scored the highest and the $\mathrm{S}$ wines scored the lowest for overall quality, with significant differences. Taste scoring showed the same trend as for overall quality; aroma and appearance had similar trends, although no significant differences were observed.

Considering that bush vines and $\mathrm{S}$ systems have a similar canopy architecture, it may be expected that they produce wines with similar characteristics. However, the quality scoring for $\mathrm{S}$ wines in the current study and in that of Van Zyl and Van Huyssteen (1980b) are conflicting. In the investigation by Van Zyl and Van Huyssteen (1980b), the Chenin blanc wines from bush vines were rated the highest based on colour, whereas in the current study, the wines from similar canopy architecture (S) systems scored the lowest among all the systems.

Aroma, taste and mouthfeel played a part in the qualityassessment scores in the present work, whereas appearance (colour) had no significant influence. Similar findings by Valentin et al. (2016) show that colour was not the major contributor to the overall quality of Sauvignon blanc and Pinot noir wines in a study comparing Burgundy wines to New Zealand wines. In contrast, Van Zyl and Van Huyssteen (1980b) found colour to be a determinant in Chenin blanc wine quality differences; however, the cause of colour differences were the result of grapes infected by fungus, rather than driven by canopy microclimates.

\section{CONCLUSIONS}

It is significant for winegrowers to make the right choice of trellising system that can maintain or even improve wine organoleptic properties and overall quality. One way to evaluate the improvement of sensory characteristics and quality aspects is to profile the resultant wines. The current work evaluated the effects of wines made from grapes grown on six different trellising systems regarding sensory characteristics and quality rating using CATA for profiling and quality assessment.

Regardless of the panel (experts or analytical), it was shown that the different trellising systems in this study did not effect the aroma perception of the Chenin blanc wines. One possible major factor could be that Chenin blanc grapes are neutral - which means they lack a typical character and hence their aroma is highly dependent on the winemaking process rather than on viticultural practices.

On the other hand, taste and mouthfeel were affected more prominently, as the systems have an impact on the phenolic compounds responsible for mouthfeel and on other compounds, as discussed in the text (sugar levels at harvest correlated with alcohol levels in the resulting wines). The differences in taste and mouthfeel further played a role in the wines' quality scores. Wines from the $\mathrm{S}$ system were associated with negative attributes, such as 'acidity', 'light body', 'watery' and 'short aftertaste' and scored the lowest. In brief, with regard to trellising system there is no one size that fits all. Under equitable conditions in the same vineyard, there were differences in aspects related to taste, mouthfeel and quality, but not aroma. These results should be considered carefully before extrapolating them to wines from a vineyard with a different terroir and, more specifically, to wines from a different cultivar. This is particularly also so in the light of climate change, drought and consumers requiring loweralcohol wines. Choosing a trellis should be based on the objectives of the winemaker, but should not underrate the significance of consumer preferences and economic factors.

The chemical composition of grapes is an important aspect in winemaking, as it determines the characteristics of the wine, in addition to the fermentation and ageing processes. The content, concentration and level of certain compounds in grapes can be modified by several factors, including vineyard practices. One possible way of evaluating the impact of vineyard practices, including trellising systems, on wine characteristics is through analytical methods. Chemical composition entails volatile and non-volatile compounds that contribute to defining wine typicality and style. Vines on similar types of trellises were found to have similar responses to nitrogenous compounds like amino acids and the yeast assimilable nitrogen components of their juice. The amino acid profile made it possible to differentiate the musts from the TF and L systems, which were different from the that of the rest of the systems. Even if individual and groups of amino acids varied between systems, the differences did not reflect in the major volatile composition of the wines, in particular in the amino acids that are involved in ester production.

Differences were not apparent between the systems based on the volatile composition of the wines. Again, vines on the horizontal dividing or open canopy type of trellis (L and TF) in this study had higher concentrations of thiol compounds and major volatiles than the rest of the systems, although they were comparable in practical terms.

According to the profiles provided in this study, the trellising systems may influence other wine aspects, as revealed by HRMS fingerprinting. Other than that, factors such as variety, vineyard location, vintage, water usage and yield could be enough tools for wine growers to make decisions on the type of system to use. The results of this study have to be considered carefully before extrapolation to other regions or cultivars, because of the genetic makeup of a vine or cultivar and its response to external factors, or because of other aspects such as clones.

\section{LITERATURE CITED}

Adams, J., Williams, A., Lancaster, B. \& Foley, M., 2007. Advantages and uses of check-all-that-apply response compared to traditional scaling of attributes for salty snacks. In: 7th Pangborn Sens. Sci. Symp. Aug. 2007. $12-418$.

Ashraf, M. \& Foolad, M.R., 2007. Roles of glycine betaine and proline in improving plant abiotic stress resistance. Environ. Exp. Bot. 59(2), 206-216.

Atanassov, I., Hvarleva, T., Rusanov, K., Tsvetkov, I. \& Atanassov, A., 2009. Wine metabolite profiling: Possible application in winemaking and grapevine breading in Bulgaria. Biotechnol. Biotechnol. Equip. 23(4), 1449-1452.

Augustyn, O.P.H. \& Rapp, A., 1982. Aroma components of Vitis vinifera L. cv. Chenin blanc grapes and their changes during maturation. S. Afr. J. Enol. Vitic. 3(2), 47-51 
Bell, S. J., \& Henschke, P. A. (2005). Implications of nitrogen nutrition for grapes, fermentation and wine. Aust. J. Grape Wine Res. 11(3), 242-295.

Botha, A., 2015. The use of different oak products during the fermentation and ageing of Chenin blanc: Sensory properties, perceived quality, and consumer preference. Thesis, Stellenbosch University, Private Bag X1, 7602 Matieland (Stellenbosch), South Africa.

Bruwer, F.A., 2018. Effect of foliar nitrogen and sulphur spraying on white wine composition (Vitis vinifera L. cv. Chenin blanc and Sauvignon blanc). Thesis, Stellenbosch University, Private Bag X1, 7602 Matieland (Stellenbosch), South Africa.

Buica, A. \& Panzeri, V., 2018. Thiols in Young South African Chenin Blanc Wine. WineLand. available at https://www.wineland.co.za/thiols-in-youngsouth-african-chenin-blanc-wine/. Accessed 19 June 2020.

Buica, A., Brand, J., Wilson, C. \& Stander, M., 2017. Evaluating South African Chenin blanc wine styles using an LC-MS screening method. Stud. U. Babes-Bol Che. 62(2), 113-123.

Charters, S. \& Pettigrew, S., 2006. How effectively do we communicate about wine? Proc. 3rd Int. Wine Bus. Res. Conf., July 2006, Montpellier, France. pp. CDROM.

Conde, C., Silva, P.F., Fontes, N., Dias, A.C.P., Tavares, R.M., Sousa, M.J., Agasse, A., Delrot, S. \& Gerós, H., 2007. Biochemical changes throughout grape berry development and fruit and wine quality. Food 1(1), 1-22.

Drenjančević, M., Rastija, V., Jukić, V., Zmaić, K., Kujundžić, T., Rebekić, A. \& Schwander, F., 2018. Effects of early leaf removal on volatile compounds concentrations in Cabernet Sauvignon wines from the Ilok vineyards. Poljoprivreda 24(1), 10-17.

Du Plessis, C.S. \& Augustyn, O.P.H., 1981. Initial study on the guava aroma of Chenin blanc and Colombar wines. S. Afr. J. Enol. Vitic. 2(2), 101-103.

Ferreira, V., López, R. \& Cacho, J.F., 2000. Quantitative determination of the odorants of young red wines from different grape varieties. J. Sci. Food Agric. 80(11), 1659-1667.

Ford, R.J., 2007. The effect of shading and crop load on flavour and aroma compounds in Sauvignon blanc grapes and wine. MSc thesis, Lincoln University, New Zealand.

Friedel, M., Stoll, M., Patz, C.D., Will, F. \& Dietrich, H., 2015. Impact of light exposure on fruit composition of white "Riesling" grape berries (Vitis vinifera L.). Vitis - J. Grapevine Res. 54(3), 107-116.

Gawel, R., Smith, P.A., Cicerale, S. \& Keast, R., 2018. The mouthfeel of white wine. Crit. Rev. Food Sci. Nutr. 58(17), 2939-2956.

Gregan, S.M., Wargent, J.J., Liu, L., Shinkle, J., Hofmann, R., Winefield, C., Trought, M. \& Jordan, B., 2012. Effects of solar ultraviolet radiation and canopy manipulation on the biochemical composition of Sauvignon blanc grapes. Aust. J. Grape Wine Res. 18(2), 227-238.

Harsch, M.J., Benkwitz, F., Frost, A., Colonna-Ceccaldi, B., Gardner, R.C. \& Salmon, J.-M., 2013. New precursor of 3-mercaptohexan-1-ol in grape juice: Thiol-forming potential and kinetics during early stages of must fermentation. J. Agric. Food Chem. 61(15), 3703-3713.

Helwi, P., Guillaumie, S., Thibon, C., Keime, C., Habran, A., Hilbert, G., Gomes, E., Darriet, P., Delrot, S. \& Van Leeuwen, C., 2016. Vine nitrogen status and volatile thiols and their precursors from plot to transcriptome level. BMC Plant Biol. 16(1), 1-23.

Jeffery, D.W Spotlight on varietal thiols and precursors in grapes and wines. 2016. Aust. J. Chem. 69(12) 1323-1330.

Ji, T. \& Dami, I.E., 2008. Characterization of free flavor compounds in Traminette grape and their relationship to vineyard training system and location. J. Food Sci. 73(4), 262-267.
Kliewer, W.M., 1970. Free amino acids and other nitrogenous fractions in wine grapes. J. Food Sci. 35(1), 17-21.

Kliewer, W.M., Bogdanoff, C. \& Benz, M., 1991. Responses of Thompson Seedless grapevines trained to single and divided canopy trellis systems to nitrogen fertilisation. In: Rantz, J.M. (ed.). Int. Symp. Nitrogen Grapes Wine, pp. $282-289$

Kobayashi, H., Takase, H., Suzuki, Y., Tanzawa, F., Takata, R. \& Fujita, K., 2011. Environmental stress enhances biosynthesis of flavor precursors, S-3(hexan-1-ol )-glutathione and S-3-(hexan-1-ol )-L-cysteine, in grapevine through glutathione S-transferase activation. J. Exp. Bot. 62(3), 1325-1336.

Lawless, H.T. \& Heymann, H., 2010 (2 $2^{\text {nd }}$ ed). Sensory Evaluation of Food Principles and Practices. Springer, New York.

Lawrence, N., 2012. Volatile metabolic profiling of SA Chenin blanc fresh and fruity and rich and ripe wine styles: Development of analytical methods for flavour compounds (aroma and flavour) and application of chemometrics for resolution of complex analytical measurement. Thesis, Stellenbosch University, Private Bag X1, 7602 Matieland (Stellenbosch), South Africa.

Lloyd, N., 2013. Varietal Thiols and Green Characters. Australian Wine Research Institute, Adelaide, South Australia.

Louw, L., Tredoux, A.G.J., Van Rensburg, P., Kidd, M., Naes, T. \& Nieuwoudt, H.H., 2010. Fermentation-derived aroma compounds in varietal young wines from South Africa. S. Afr. J. Enol. Vitic. 31(2), 213-225.

Ljungdahl, P. O., \& Daignan-Fornier, B. (2012). Regulation of amino acid, nucleotide, and phosphate metabolism in Saccharomyces cerevisiae. Genetics, 190(3), 885-929.

Mafata, M., Stander, M., Thomachot, B., Buica, A., Mafata, M., Stander, M.A., Thomachot, B. \& Buica, A., 2018. Measuring thiols in single cultivar South African red wines using 4,4-Dithiodipyridine (DTDP) derivatization and Ultraperformance Convergence Chromatography- Tandem Mass Spectrometry. Foods 7, 9, 138

Marais, J., 1983. Terpenes in the aroma of grapes and wines. S. Afr. J. Enol. Vitic. 4(2), 49-58.

Marais, J. \& Rapp, A., 1988. Effect of skin-contact time and temperature on juice and wine composition and wine quality. S. Afr. J. Enol. Vitic. 9(1), $22-29$.

Marais, J., Hunter, J.J. \& Haasbroek, P.D., 1999. Effect of canopy microclimate, season and region on Sauvignon blanc grape composition and wine quality. S. Afr. J. Enol. Vitic. 20(1), 1-30.

Marais, J., Van Rooyen, P.C. \& Du Plessis, C.S., 1981. Classification of white cultivar wines by origin using volatile aroma components. S. Afr. J. Enol. Vitic. 2(2), 45-49.

Marais, J., Van Wyk, C.J. \& Rapp, A., 1992. Effect of sunlight and shade on norisoprenoid levels in maturing Weisser Riesling and Chenin blanc grapes and Weisser Riesling wines. S. Afr. J. Enol. Vitic. 13(1), 23-32.

Morrison, J. \& Noble, A., 1990. The effects of leaf and cluster shading on the composition of Cabernet Sauvignon grapes and on fruit and wine sensory properties. Am. J. Enol. Vitic. 41(3), 193-200.

Nieuwoudt, H.H., Prior, B.A., Pretorius, I.S., Manley, M. \& Bauer, F.F., 2004. Principal component analysis applied to Fourier transform infrared spectroscopy for the design of calibration sets for glycerol prediction models in wine and for the detection and classification of outlier samples. J. Agric. Food Chem. 52, 12, 3726-3735.

Niimi, J., Boss, P.K. \& Bastian, S.E.P., 2018. Sensory profiling and quality assessment of research Cabernet Sauvignon and Chardonnay wines; quality discrimination depends on greater differences in multiple modalities. Food Res. Int. 106, 304-316.

Panzeri, V., Brand, J. \& Buica, A., 2019. Mapping the 2017 Absa Top 10 Pinotage wines - Chemistry and sensory perspectives. WineLand. 
Parish-Virtue, K., Herbst-Johnstone, M., Bouda, F. \& Fedrizzi, B., 2019. The impact of postharvest ultra-violet light irradiation on the thiol content of Sauvignon blanc grapes. Food Chem. 271, 747-752.

Pereira, G.E., Gaudillere, J.P., Pieri, P., Hilbert, G., Maucourt, M., Deborde, C., Moing, A. \& Rolin, D., 2006. Microclimate influence on mineral and metabolic profiles of grape berries. J. Agric. Food Chem. 54(18), 67656775 .

Petrovic, G., Kidd, M. \& Buica, A., 2019. A statistical exploration of data to identify the role of cultivar and origin in the concentration and composition of yeast assimilable nitrogen. Food Chem. 276, 528-537.

Peynaud, E. \& Blouin, J., 1996 ( $2^{\text {nd }}$ ed). The taste of wine. John Wiley and Sons, New York.

Rasinski, K.A., Mingay, D. \& Bradburn, N.M., 2002. Do respondents really "mark all that apply" on self-administered questions? Public Opin. Q. 58(3), 400-408.

Reynolds, A.G. \& Vanden Heuvel, J.E., 2009. Influence of grapevine training systems on vine growth and fruit composition: A review. Am. J. Enol. Vitic. 3, 251-268.

Reynolds, A.G., Edwards, C.G., Cliff, M.A., Thorngate, J.H. \& Marr, J.C., 2001. Evaluation of yeast strains during fermentation of Riesling and Chenin blanc musts. Am. J. Enol. Vitic. 52(4), 336-344.

Reynolds, A.G., Wardle, D.A. \& Naylor, A.P., 1996. Impact of training system, vine spacing, and basal leaf removal on Riesling. Vine performance, berry composition, canopy microclimate, and vineyard labor requirements. Am. J. Enol. Vitic. 47(1), 63-76.

Reynolds, A.G., Wardle, D.A., Cliff, M.A. \& King, M., 2004. Impact of training system and vine spacing on vine performance, berry composition, and wine sensory attributes of Riesling. Am. J. Enol. Vitic. 55(1), 96-103.

Ribéreau-Gayon, P., Glories, Y., Maujean, A. \& Dubourdieu, D., 2006 ( $\left.2^{\text {nd }} \mathrm{ed}\right)$. Handbook of Enology, The Chemistry of Wine: Stabilization and Treatments. Vol. 2. John Wiley \& Sons, Chichester, West Sussex.

Rubert, J., Lacina, O., Fauhl-Hassek, C. \& Hajslova, J., 2014. Metabolic fingerprinting based on high-resolution tandem mass spectrometry: A reliable tool for wine authentication? Anal. Bioanal. Chem. 406, 6791-6803.

Salvatore, E., Cocchi, M., Marchetti, A., Marini, F. \& de Juan, A., 2013. Determination of phenolic compounds and authentication of PDO Lambrusco wines by HPLC-DAD and chemometric techniques. Anal. Chim. Acta 761, 34-45.

Šebela, D., Turóczy, Z., Olejníčková, J., Kumšta, M. \& Sotolář, R., 2017. Effect of ambient sunlight intensity on the temporal phenolic profiles of Vitis vinifera L. cv. Chardonnay during the ripening season - A field study. S. Afr. J. Enol. Vitic. 38(2), 94-102.

Somers, T.C. \& Pocock, K.F., 2015. Phenolic assessment of white musts Varietal differences in free-run juices and pressings. Vitis - J. Grapevine Res. 30 (3) 189-201.
Šuklje, K., Antalick, G., Buica, A., Langlois, J., Coetzee, Z.A., Gouot, J., Schmidtke, L.M. \& Deloire, A., 2016. Clonal differences and impact of defoliation on Sauvignon blanc (Vitis vinifera L.) wines: A chemical and sensory investigation. J. Sci. Food Agric. 96(3), 915-926.

Tominaga, T., Murat, M.-L. \& Dubourdieu, D., 1998. Development of a method for analyzing the volatile thiols involved in the characteristic aroma of wines made from Vitis vinifera L. cv. Sauvignon blanc. J. Agric. Food Chem. 46(3), 1044-1048.

Vaclavik, L., Lacina, O., Hajslova, J. \& Zweigenbaum, J., 2011. The use of high performance liquid chromatography-quadrupole time-of-flight mass spectrometry coupled to advanced data mining and chemometric tools for discrimination and classification of red wines according to their variety. Anal. Chim. Acta 685(1), 45-51.

Valentin, D., Chollet, S., Lelievre, M. \& Abdi, H., 2012. Quick and dirty but still pretty good: A review of new descriptive methods in food science. Int J. Food Sci. Technol. 47(8), 1563-1578.

Valentin, D., Parr, W.V, Peyron, D., Grose, C. \& Ballester, J., 2016. Colour as a driver of Pinot noir wine quality judgments: An investigation involving French and New Zealand wine professionals. Food Qual. Prefer. 48, 251261.

Van Rooyen, P.C. \& Tromp, A., 2017. The effect of fermentation time (as induced by fermentation and must conditions) on the chemical profile and quality of a Chenin blanc wine. S. Afr. J. Enol. Vitic. 3(2), 75-80.

Van Zyl, J. \& Van Huyssteen, L., 1980a. Comparative studies on wine grapes on different trellising systems: I. Consumptive water use. S. Afr. J. Enol. Vitic. 1(1), 7-14.

Van Zyl, J.L. \& Van Huyssteen, L., 1980b. Comparative studies on wine grapes on different trellising systems: II. Micro-climatic studies, grape composition and wine quality. S. Afr. J. Enol. Vitic. 1(1), 15-25.

Volschenk, C.G. \& Hunter, J.J., 2001. Effect of trellis conversion on the performance of Chenin blanc/99 Richter grapevines. S. Afr. J. Enol. Vitic. 22(1), 31-35

Wilson, C.L., 2017. Chemical evaluation and sensory relevance of thiols in South African Chenin blanc wines. Thesis, Stellenbosch University, Private Bag X1, 7602 Matieland (Stellenbosch), South Africa.

Zoecklein, B.W., Wolf, T.K., Duncan, S.E., Marcy, J.E. \& Jasinski, Y., 1998. Effect of fruit zone leaf removal on total glycoconjugates and conjugate fraction concentration of Riesling and Chardonnay (Vitis vinifera L.) grapes. Am. J. Enol. Vitic. 49(3), 259-265.

Zoecklein, B.W., Wolf, T.K., Pélanne, L., Miller, M.K. \& Birkenmaier, S.S., 2008. Effect of vertical shoot-positioned, Smart-Dyson, and Geneva double-curtain training systems on viognier grape and wine composition. Am. J. Enol. Vitic. 59(1), 11-21. 